\title{
Competition Theory and Channeling Explanation
}

\author{
Christopher H. Eliot ${ }^{\S}$
}

The complexity and heterogeneity of causes influencing ecology's domain challenge its capacity to generate a general theory without exceptions, raising the question of whether ecology is capable, even in principle, of achieving the sort of theoretical success enjoyed by physics. Weber has argued that competition theory built around the Competitive Exclusion Principle (especially Tilman's resource-competition model) offers an example of ecology identifying a law-like causal regularity. However, I suggest that as Weber presents it, the CEP is not yet a causal regularity. Instead, I argue that the scientific understanding in Tilman's theory takes a different form. The theory explains through a structure I call "channeling explanation" which does not depend on deduction from general laws, but rather builds on constraints and trade-offs represented in state-space. Recognizing this structure supports the more general point that ecology and other so-called special sciences can reveal novel theoretical approaches to philosophy of science when approached with openness to their uniqueness.

\author{
KEYWORDS \\ Ceteris paribus clauses $\bullet$ Competitive exclusion principle $\bullet$ Ecology $\bullet$ Explanation $\bullet$ \\ Laws $\bullet$ Plant succession $\bullet$ Resource competition $\bullet$ Tilman (David)
}

\section{Introduction}

Philosophy of science cut its teeth this last century describing ideal science by drawing on the estimable model of established parts of physics. Following physicists' successes at articulating necessary, universal laws, philosophers of science held up laws of science as the pith of ideal scientific theories. They scrutinized what kinds of generalizations can count as laws. Yet, also during the twentieth century, scientific research and scientific disciplines proliferated, and very little of the resulting knowledge has yielded necessary, universal laws. How should we assess whether any of these disciplines is theoretically successful? Three options present themselves: (1) we can treat their knowledge as embryonic and maturing into the profile of physics, (2) we can relax and expand definitions of laws so their knowledge becomes lawful under the new definitions, or (3) we can explore whether their theory might be epistemically robust despite having a different, lawless structure.

This essay takes the third approach to part of ecology, less from an a priori conviction that ecology cannot have laws than from curiosity about whether ecology looks more accomplished when measured against a standard other than the Newtonian Ideal - the ideal that successful science is built around necessary, universal laws (Lewontin 2003). It pursues whether ecology offers up any such alternative

$\S$ Department of Philosophy, Hofstra University, 104F Heger Hall, Hempstead, NY USA

E-mail: Christopher.H.Eliot@hofstra.edu

Received 7 July 2010; Revised 4 January 2011; Accepted 5 January 2011 
standards if approached with an eye towards theoretical structures other than laws. Specifically, it scrutinizes a body of ecological theory in which philosopher Marcel Weber (1999) has argued that we can find law-like generalizations, and argues that its explanatory resources become clearer if it is understood differently. The immediate upshot is recognizing a form of explanation which is not nomothetic (i.e., law-based). This is not to say that the competition theory in question is uniquely suggestive of an alternative analysis. To the contrary, Weber engages this body of theory because it is exceptionally suggestive of a law or laws. My contention is that even if this best-candidate theory can productively be analyzed in different terms, that outcome recommends further open-minded investigation of theory-structures, both in ecology and across a range of flourishing but lawless disciplines.

Specifically, Weber's (1999) interest is ecology's Competitive Exclusion Principle (CEP). He argues that while not a necessary, universal generalization, the CEP can be interpreted as a causal regularity of the sort defined by Waters (1998). Though the GEP faces exceptions, Weber argues for its lawfulness by drawing on ecologist David Tilman's (1982) resource-competition theory, contending that Tilman's theory contextualizes the CEP and so identifies and explains cases where the CEP does not hold. Weber suggests that though the CEP faces exceptions, a class of them is filled in by Tilman's theory, and that even if further exceptions remain to be filled in, this produces a template for ecological progress in which the inaccuracies of central, explanatory laws are plugged up by wads of ancillary regularities. I argue to the contrary that the understanding in Tilman's theory - even if it is feasible to reconstruct it as lawful - is better understood as explaining through an approach I call "channeling explanation." That is, the body of theory Weber uses from Tilman has a further context. It is explained by Tilman in a way that relegates regularities to the background.

\section{Responses to Lawlessness}

Before philosophy of ecology emerged, a key turn in philosophy of biology's adolescence of the early 1980s came with philosophers (e.g., Beatty 1981) resolving that if evolutionary biology fails to resemble existing frameworks for explanatory theory, so much the worse for those frameworks. Evolutionary biology and genetics, it was recognized, offer such robust explanatory theory that if they do not fit neatly into philosophical accounts of theory-structure and explanation, philosophy of science should investigate how they represent and explain rather than treating them as "immature" (in the sense of Nagel 1961). Then, with biological cases newly sanctioned as starting points for understanding adult science, debate over alternative frameworks for making sense of them spurred philosophy of biology's growth.

Now, philosophy of ecology faces puberty. The direction of its maturation turns on whether ecology is both sufficiently robust and sufficiently different to motivate modifying or extending philosophy of science. Otherwise, ecology will remain a domain for applying philosophy of science. An entirely applied philosophy of ecology could be worthwhile, but would lead a cloistered existence, while the philosophies of physics, evolutionary biology, and psychology have thrived by not similarly confining themselves. If philosophy of ecology can develop along these lines, its challenge becomes offering something back to philosophy of science.

Unfortunately, there are reasons to treat ecology as immature in Nagel's (1961) sense, even doomed to protracted adolescence. Its theory, nearly all less than a century old, confronts a heterogeneous domain with an unsettled ontology, diverse and obscure causal interactions, and few clearly-bounded systems or processes. These difficulties suggest broad and narrow pessimisms. A broad pessimism places ecology within a range of disciplines unable to produce laws because of the complexity of their domains. Cooper (2003) observes that "the theoretical tradition in ecology has been driven by the goal of finding simple quantitative laws, the kind of laws that would put ecology on all fours with the more secure sciences" (133). However, causal complexity might create exceptions for any potential laws, making them either false or in need of being qualified as ceteris paribus, or "all else being equal." If ceteris paribus-qualification can render statements vacuous, in so far as any general statement with at least one confirming instance may be true when so qualified, ceteris paribusqualified generalizations should not be treated as substantive truths. Without laws, ecology remains a stunted imitation of physics. Earman and Roberts (1999), for example, recognizing the exceptions riddling the 
generalizations of most sciences, argue against the many attempts to understand them as substantive, but ceteris paribus-qualified, laws. In their estimation, non-physical sciences now require not philosophers' efforts to figure out how to render their laws substantial by analyzing ceteris paribus clauses, but rather better science. Better science might yield laws or near-laws like they conclude relativity theory has. If ecology's domain resists laws, ecologists should work harder. Alternately, a more focused pessimism targets ecology's special difficulties with identifying laws. Shrader-Frechette and McCoy (1993) and Peters (1991) think it misguided for ecology to seek explanatory laws, and instead sketch out successful ecological theory as merely particular - as a matter for case studies and local understandings rather than general theory. Sarkar (1996), too, argues that given an immediate need for ecological guidance in the face of conservation crises, case studies offer more value than general principles.

Less pessimistic responses from philosophers to the gap between current ecology and the Newtonian Ideal have generally taken one of two forms suggested above: relaxing philosophical definitions of "law," or making sense of ecological theory's relationship to the world without them. Cooper writes, "if our concept of law prevents us from recognizing laws in ecology, that does not mean that ecology is destined to become a science of case studies ... It means that we need a new concept of law" and, more generally, a "better, more realistic image of successful science" (2003, 113). Philosopher Marc Lange (2002) argues that ecology's Species-Area relationship can count as a law, but only at the cost of defining laws as reliable inference rules rather than necessary, universal generalizations without other features philosophers have required for laws like supporting counterfactuals (i.e., "had the cause not obtained, the effect would not have either"). A number of ecologists have taken this approach, too, like Lawton (1999), Poulin (2007), and Dodds (2009). They eagerly identify laws, but at the cost of accepting rough, local generalizations as "laws." This approach elevates ecology even more if one is willing to argue that even the generalizations of physics have achieved only some similar, weaker status.

Another optimistic strategy is to treat theoretical claims - whether they have the form of laws or not - as having a different relationship to the world. For example, having been a popular alternative for making sense of evolutionary biology amid doubts about its laws (Lloyd 1988; Thompson 1988), the Semantic View of theories has been transposed to ecology (Castle 2001). (Not all versions of the Semantic View address themselves to the problem of exceptions to laws, but Suppe [2000] and Beatty [1981] are explicitly motivated by it.) The Semantic View is a set of variations on the idea that scientific theories are families of models. Some versions of the Semantic View hold that models do not make claims about the world directly. However, the Semantic View does not on its own illuminate how or why some models explain better than others. Alternatively, Cooper (2003) has recommended understanding ecological claims as justified by claims about capacities, as on Cartwright's (1989) model. In that case, the explanatory power of theoretical claims in ecology would derive from their relationships to the capacities or powers its individuals have (e.g., swallows can eat a hundred flies an hour). However, empiricists, believing that only what is observable belongs in science, have long doubted whether capacities are observable, and suggested that unobservable properties cannot ground explanations. Yet, if one can overcome such doubts, this approach makes up for a lack of invariant generalizations. Even so, generating explanations from capacities requires knowledge ecologists rarely have, especially if the aim is to build up to general theory from individual organisms' capacities. Cartwright (2002) comments,

We know for the powers of physics when they will be exercised (e.g., a massive object always attracts other masses); and ... we have rules for how to calculate what happens when different capacities operate together (e.g., the vector addition law for forces). This kind of knowledge is missing for many other subjects. That is why they cannot make exact predictions" (429).

Such missing knowledge challenges hanging ecological explanation and prediction on the capacities of its individuals.

Thus, a variety of options are available for making sense of ecology's scientific strength. What standard should we use to decide among them? I suggest that the appropriate philosophical account of ecology is the one that best captures its predictive and/or explanatory successes. Though it may be possible to unify ecology's diverse bodies of theory (as Roughgarden [2009] and Vellend and Agrawal [2010] suggest), 
different philosophical accounts may be necessary for different parts of ecology. If an imitation of physics's strict laws is the best ecology can be understood as achieving, then that is how we should understand it. But let us see.

\section{The Competitive Exclusion Principle as Gausal Regularity}

Like Colyvan and Ginzburg (2003) and Ginzburg and Colyvan (2004), Weber (1999) argues that ecology has laws - if not necessary, universal ones, then something close enough. Specifically, he believes that the Competitive Exclusion Principle (CEP) serves as a law that grounds explanations of community dynamics. Not only does he conclude that the CEP serves as a law, but also that it stands up to Beatty's (1995) evolutionary contingency objection that there are no genuine biological laws because biology's lawcandidates are either contingent or not distinctively biological. (They would not be distinctively biological if made true by chemistry or physics.) Weber's strategy is to demonstrate that while the CEP has exceptions, the exceptions are produced by identifiable circumstances ecologists understand. Therefore, it need not be qualified with a potentially vacuous ceteris paribus clause.

Loosely expressed, the CEP claims that populations of different species cannot coexist for long on the same resources. Confusingly, it has been rendered more precise in different ways, reflecting its multiple origins. Udvardy (1959) traces its explicit statement back to Joseph Grinnell (Grinnell 1904, 372), though Hardin (1960) notes the earlier passage from On the Origin of Species in which Darwin anticipates the CEP by asserting that struggles for resources lead inevitably to extinctions of some competitors. The principle itself has taken various forms as it is used to analyze community dynamics. Hardin, for instance, treats the CEP as describing a phenomenon arising from species' differences. For him, it asserts that minute differences between competing species with respect to their efficiency in converting resources into offspring are sufficient to produce the local extinction of one of them, ceteris paribus (Hardin 1960, 1293). Other expressions of the principle emphasize similarities between species as producers of extinctions. Weber employs such a version derived from G. Evelyn Hutchinson, who uses the CEP to analyze the mystery of plankton coexisting on shared resources in a homogeneous marine environment. Following this classic analysis, Weber renders the CEP as expressing that "species with insufficiently differentiated fundamental niches cannot coexist at equilibrium" (76). Hutchinson's "fundamental niche" concept refers to a region in an abstract, multidimensional state-space defining the circumstances a species is specialized to live in, where each dimension represents a habitat feature. For him, the CEP suggests that ecological similarities among species, described as significantly-overlapping fundamental niches, produce exclusion (Hutchinson 1957; 1961). (For the CEP's history, see Kingsland [1995]).

Weber uses the CEP with Tilman's elaboration to argue that ecology has at least this law-like regularity. More generally, for Weber identifying this law reveals that "law-like statements play an important role in scientific theories of this kind," and in the explanations they offer (71). And further, even if Weber intends his title mainly as allusion to Duhem and not as an assertion of comprehensiveness, identifying the law should illuminate "The Aim and Structure of Ecological Theory." While Weber does not explicitly couch his agenda in terms of the status of ecology, that ecology has realized its aim of building theory around laws serves to elevate evolutionary biology, against which he invokes a contrast in his first sentences: "Why should evolution be lawful, and ecological processes not?" (71). The CEP is a candidate, and against this standard Weber suggests, "ecology knows evolutionarily invariant generalizations which are law-like and at the same time distinctively biological" (91).

To characterize its lawfulness, Weber recommends the CEP as an instance of a "causal regularity" of the sort described by Waters (1998), who uses the concept to refer to the specific kind of stable, noncontingent regularities he suggests widely undergird biological explanations. In the critique of biological laws Weber aims to resist, Beatty (1995) argues that since biological kinds are contingent because they evolved, any laws covering them will be contingent as well. Waters claims that though generalizations concerning the distribution of biological kinds hold, if at all, contingently-perhaps unlike those concerning physical kinds - much explanatory knowledge in biology can be rendered as non-contingent generalizations. These generalizations are causal regularities like (his example) that blood vessels containing sufficient elastin 
expand when internal pressure increases. The advantage causal regularities have over necessary laws as frameworks for understanding biology is that they are necessarily true of certain entities, despite their range of application being contingent. Waters suggests that a separate class of generalizations expresses the contingent distributions of biological kinds. And so, the truth of causal regularities is not undermined by evolutionary contingency.

A problem with treating the CEP as a causal regularity in Waters's sense arises because causal regularities "pick out a theoretical kind marked by a uniform internal make-up that causes its tokens to behave in uniform ways" (24). Physiological similarities among related organisms - mammalian eyes dilate when ambient light decreases and do so because of their common structure - comprise one class of examples. However, ecological niche overlap and differentiation are not usually entirely functions of "internal make-up" or physiology. Organisms with very different physiologies sometimes have significantlyoverlapping niches (and limiting-resource requirements), like nightjars and insectivorous bats. Organisms with very similar physiologies frequently have different niches because of habitat differences. Consequently, the CEP conforms better to the third kind of generalization in Waters's classificatory scheme. It better resembles a "functional generalization," a rule applying to "behavior exhibited by entities with quite different internal make-ups" (24-25). Functional generalizations ride on top of sets of causal regularities, bringing the phenomena they describe under a single description, despite a lack of internal uniformity. Waters's example comes from classical genetics: "whenever allele $a$ is dominant to allele $b$, organisms with the $a b$ genotype will exhibit the trait associated with the $a$ allele" (24). In this case, dominance is a functional concept, not a feature of common internal make-up.

However, in Waters's scheme functional generalizations are true by definition. They need to be, to block contingency. Causal regularities resist contingency because they cite common structures as necessitating effects, and functional generalizations do not assert such necessitation. Though Weber should thus treat the CEP as a functional generalization, there are compelling reasons not to treat it as a tautology - as true by definition - even if it sometimes has been. Though one early formulator of the CEP, Georgii Gause, believed the principle empirically falsifiable, later ecologists endorsed its logical truth. Garrett Hardin, especially, in an article with the CEP as its title declares that "the 'truth' of the principle is and can be established only by theory, not being subject to proof or disproof by facts, as ordinarily understood" (1960, 1293). His central premise is that the principle would be very difficult to prove or disprove empirically, because a fundamental niche is an abstract property of a group of organisms, and extremely difficult to characterize precisely (even if it were rigid - something evolution, niche construction, variation within and among populations, and developmental plasticity each offer reasons to doubt). That is, the co-existence of any two competing populations may count as a departure from the CEP, but may also result from their occupying slightly different niches. Along these lines, Begon et al. (1990) note the "very real methodological problem in positively establishing the pertinence of the competitive exclusion principle in any particular situation," because where competition is observed, "it is often difficult to establish positively that there is niche differentiation, and it is impossible to prove the absence of it" (252). However, methodological challenges and conceptual imprecision per se do not a tautology make. Stronger reasons for the CEP's logical truth are its derivability from theory, specifically from one version of the Lotka-Volterra competition equations (Gotelli 2008), and the possibility that competitive exclusion is entailed by the very concepts of "fundamental niches" and their "sufficient differentiation." In this latter case, any niche as such would need to be distinct from others, and significant overlap among niches would entail competition to the point of exclusion simply because exclusive occupation defines a prerequisite for lasting survival. Contra Gause, these considerations support its logical truth.

However, semantics in this case can usefully follow practice, and the CEP has repeatedly been subjected to testing, and so employed empirically. Ecologists" repeated testing entails that "niche" is being used in a way that is consistent with the possibility of permanent overlap. Thomas Park's (1948) experiments on flour beetles are early examples of this body of work, and I mention two other examples below. Such testing suggests that ecologists have not always treated the CEP as true by definition, and in that case, not only can it not be a causal regularity (because it faces exceptions), it cannot be a functional generalization either (because it is not a logical truth). 


\section{Exceptions to the GEP: Leaks, Stoppers, and Leaky Stoppers}

Ultimately, to serve explanation as a causal regularity (sensu Waters 1998), Weber needs the CEP to at least be true. Yet, it is riddled with known exceptions. That is, there is not a version of it we know to be true. Two exceptional cases Weber acknowledges are where a predator on two competing species suppresses their numbers such that they never become sufficiently abundant to compete for resources, and where "the competition process is periodically interrupted, e.g. by population reductions, [such that] competitive exclusion may not proceed to completion" (77). Other exceptions include cases where resources are not limiting and where density-dependence is nonlinear (Gotelli 2008, 114-115), and where the competitors are two functionally-identical species, physiologically and morphologically similar enough to have identical ecological footprints, despite distinct evolutionary lineages. In light of such exceptions, the CEP begins to resemble less a causal regularity than a ceteris paribus generalization.

Acknowledging this, Weber insists the CEP's exceptions do not threaten its lawfulness. He finds Hutchinson suggesting that the CEP "is true except in cases where there are good reasons not to expect it to be true," and he interprets this to mean that the conditions defeating the CEP can be specified antecedently (Hutchinson 1957, 419). Helpfully, a list of known exceptions would not force a generalization into a dilemma between falsehood and vacuous ceteris paribus qualification, because the list of exceptions itself (rather than a ceteris paribus-clause) could be appended to the CEP. Considering a few examples of ecologists predicting exceptions to the GEP on the basis of theory, Weber remarks optimistically that "ecologists have been quite successful in spelling out conditions that restrict the principle's domain of application" (78). But (as one of Weber's reviewers also pointed out) that we anticipate in advance some exceptions or domain restrictions is beside the point; if we are interested in lawfulness in Waters's sense, we want to know whether all the limitations on the GEP can be specified in advance. Otherwise it is a classically problematic ceteris paribus generalization.

Acknowledging that not all exceptions are known, Weber recommends that knowledge shy of full understanding is adequate: "while a complete list of such mechanisms [producing exceptions] may not be available at present, theory provides an abstract scheme for all these mechanisms." Like Marc Lange's (1993) solution to the ceteris paribus problem, Weber's supposes that ecologists have a "theoretical understanding" of conditions producing exceptions, here in the form of "abstract mechanism." More than this is required, Weber reasons, only if one is committed to deductivism about explanation - to the view that what is explained can be logically derived from explaining statements. Yet, ceding deduction as a scientific goal, we thereby cede the core motivation for finding ecological theory that can be mapped on to the Newtonian Ideal. Possessing laws confers status on a discipline mainly because laws offer deductive rigor. If the point of identifying a body of research within it that includes laws is to recognize ecology's status as a mature discipline, then abandoning the feature conferring that status undercuts the project's motivation. Or it does so unless imperfect laws supplemented with something like "abstract scheme" are as good as laws, or they are not as good but are the best ecology can do. The question becomes whether one of these is so.

The only way to assess this question is to observe whether ecologists in practice treat the CEP (assisted by their tacit understanding) as true across a known range of applications. Despite Hutchinson's optimism, that ecologists actively test particular systems for conformity to the CEP tells against the field having such tacit knowledge. As early as Park, ecologists have expressed ignorance about why and when apparent competitive exclusions occur. In Park's two-species competition experiments, one species reliably collapsed, but time to extinction varied from 180 to 1470 days, which species disappeared was unpredictable, and Park could not explain why one or the other had gone extinct even retrospectively. More recently, Silvertown (1983) determined that "competitive exclusion and niche separation are not important phenomena" in limestone pavement habitat because plants coexist there, but for unknown reasons, perhaps because of regular disturbances but perhaps not. Kullberg (1982) found that in algal communities the expectations of the CEP are not met, but for unknown reasons: "this is paradoxical in accordance with the concepts of the competitive exclusion principle. Uniformity should not lead to diversity and yet, under this most uniform of natural environments, diversity is maintained during the seral stages, and hierarchical order is sustained" (242). That is, the persistence of research programs testing the CEP and the inability to specify 
the causes of exceptions tells against ecologists having a tacit understanding of the causes of the full range of exceptions to the CEP.

Yet, as I mentioned, Weber also makes a case for one particular abstract mechanism that fills in a major exception to the CEP. Treating the CEP as a "source law," in Elliott Sober's (1984) sense - as describing a default state against which disturbing forces act-Weber offers that the CEP "suggests a 'default' scenario which raises the question of why so many plant species can generally subsist on a small number of limiting resources. Theory then postulates a mechanism, in Tilman's case an interaction of resource competition and environmental heterogeneity, which explains how species can evade competitive displacement" (85). So, in Weber's construal, Tilman identifies an exception to the CEP, then explains that exception by appealing to a mechanism explaining it, thus patching an important hole in the GEP. The exception is a case where species with overlapping niches coexist at equilibrium due to different capacities for resource-exploitation. The mechanism is a feature of a more general model of resource competition, accounts of which appear in Tilman $(1980,1982)$ and many ecology textbooks. Tilman's resource-competition model can be thought of as formalizing the idea that competitions for resources can be won by organisms able to get by on the smallest amount of essential limiting resources. If one population can make do with less than others, it can survive when they do not. Tilman designates the level of a resource a population can get by on is its " $R^{*}$," and so the model is sometimes called the $R^{*}$ model.

The $R^{*}$ model predicts a variety of specific cases where coexistence is possible for two (or more) populations with overlapping resource-requirements and competing for limiting resources. In one case, two populations competing for a single resource can coexist when they have equal $R^{*}$ values. $R^{*}$ is the level of resource availability at which a population's resource-dependent growth balances its mortality, so that it neither increases or decreases, and is in this sense at equilibrium (Tilman 1982, 44-49). That is, with more resources the population would increase, and with fewer it would decrease. If competition reduces a resource's availability to the $R^{*}$ value for one of the populations, then that population stops increasing, by definition, because its $R^{*}$ is the point at which it can no longer convert the resource into the production of enough new individuals to balance the mortality it faces. The model predicts that if species differ in their $R^{*}$ values, the availability of the resource will be depleted to the $R^{*}$ value of one of them. At this point, that population can no longer increase, while any species with lower $R^{*}$ values will continue to. Under such circumstances the model predicts the population with the lowest $R^{*}$ will competitively displace others, since it will be able to continue to increase after the others can no longer. However, in the long term, it predicts coexistence of two species when the two populations have equivalent $R^{*}$ values, and this offers the theoretical basis for the CEP-exception of interest to Weber.

The present question is whether this prediction faces any exceptions. Frustratingly, it faces many. Will two populations coexist if they have equal $R^{*}$ values? Not necessarily, if they face disease, predators, oil spills, or any of myriad other possible disturbing conditions. Can they coexist? Sure, the populations can coexist if nothing untoward interferes. However, that is not what is needed if the ambition is to defend the CEP as a strict law or causal regularity, as Weber tries to do. What is needed in that case is for the appended mechanism to be able to define the exceptional circumstances. Tilman's model does not. Just as plugs in dams must be impermeable to serve as "plugs," however, if this theoretical structure is to escape the problems motivating Weber's discussion of it, the mechanisms explaining exceptions should not themselves be subject to exceptions. By no means does this make the model useless, nor does it entail that there is no way to satisfyingly capture the model's explanatory resources in terms of generalizations. Nor does it recommend that the sequence of asserting a generalization, finding exceptions, stopping them up, finding exceptions in the stopper, stopping them up, and so on, is not a productive methodology for ecology. Rather, it suggests that if Weber has chosen the best case he can find for defending ecology's attainment of laws (the CEP with Tilman's amendment), and has chosen the best weakening of strict laws he can find (Waters's causal regularities), and many exceptions remain, it might be productive to examine the theory for explanatory structures other than laws. In fact, optimism about ecological explanation finds a basis in this body of research, I will argue, but it is a richer and uglier basis than Weber's brand of optimism recommends. 


\section{Contextualizing Resource Competition}

Given its susceptibility to disturbing conditions, Tilman's resource-competition theory just described may best be understood as a model, or as standing in some other relationship to natural systems where it is not expected to provide exceptionless, true claims. As a model it would suggest what long-term outcomes of competition would be expected under idealized conditions that were possible, if at all, only in controlled laboratory conditions. This is Bob O'Hara's (2005) conclusion, for instance, after rejecting Weber's argument for reasons similar to mine. O'Hara is optimistic about ecological generalizations, just so long as they not be called laws, as "calling them laws is to give them an epistemological status they don't deserve" (393). Other ecologists will consider this debate merely semantic, even "philosophical" in a pejorative sense. Even if approximating the Newtonian Ideal were the structure of all ecological understanding, philosophy of science would still have strategies for model improvement and standards for model success to comment on. But Weber's case is interesting because it suggests a structure that differs in more than what it is called. In Tilman's broader theory, the resource-competition model Weber analyzes is subsumed by a more general, causal theory which has the virtue of being free of exceptions.

As described above, a central variable in Tilman's resource-competition model is the reproductive or growth response of populations to resources. Yet in Tilman's body of theory, this parameter is not basic, in so far as it is explained by other properties. A species' ability to grow or reproduce in response to increased availability of certain resources is a function of its particular morphology and physiology - its shape and its functional adaptations to particular habitats. Plants vary wildly with respect to the proportion of nutrients, energy, and biomass they devote to each part of their anatomies, and thus to each of their functions. Slowgrowing woody plants, for instance, devote only $1 \%-6 \%$ of their biomass to leaves; tall perennial trees extending into forest canopy may have the vast majority of their biomass in their trunks, and less than $1 \%$ of it in leaves. In contrast, annual plants devote $50 \%-70 \%$ of their biomass to leaves; soil-dwelling algae approach allocations of $100 \%$ of biomass to their photosynthetic structures, to what are functionally their leaves (Tilman 1988, 58-60). If the primary function of leaves is photosynthesis, and therefore generating energy for rapid growth, this discrepancy appears not to be accidental. Allocations of biomass to leaves serve fast-growing plants and improve their ability to compete in the habitats they specialize in.

Accordingly, each kind of plant's capacity for converting resources into reproduction is a function of when and how it devotes resources and biomass to reproductive structures like seeds. Morphological resource allocation largely determines the ability to compete for light and soil nutrients, and this determines properties like its $R^{*}$, because a "plant with a morphology that allows it to be a superior competitor at one nutrient supply rate is necessarily an inferior competitor at higher and lower supply rates compared to plants with other morphologies" (Tilman 1988, 111). From this expectation that differential success will be due to morphology and physiology, ecologists can produce explanations for why species will grow in some rather than other circumstances. However, no single factor is predictive:

Neither photosynthetic efficiency nor allocation to roots nor any other single physiological or morphological trait of plants can predict, by itself, what should happen when two or more sizestructured plant species compete. The ability of a plant to grow and compete in a habitat with a particular resource supply rate and a particular loss rate is determined by interactions among numerous physiological, morphological, and life history traits (Tilman 1988, 94-95).

Yet these factors can be understood in a more general framework as consequences of the allocation tradeoffs forced by absolute and contextual constraints. While a typical way to incorporate numerous traits and interactions into a model would be to make them variables in an elaborate equation, Tilman treats them instead as dimensions of a state-space. The space has as its dimensions variables along which plants face constraints on growth and reproduction.

Limited nutrients and energy force on plants an allocation "decision" at both evolutionary and individual scales. Plants need to allocate resources to "photosynthetic tissues, structural and nutrient transport tissues, nutrient absorptive tissues, and reproductive tissues," which roughly correspond in vascular 
plants to "leaves, stems, roots, and seeds" (54). Were a plant to allocate all the resources available for new growth to new photosynthetic tissues, it could achieve the maximal growth possible under its light conditions (which are a resource constraint). In photosynthesis, chlorophyll, carotenoids, phycobilins and other pigments capture solar energy and retain it in ATP, which provides energy for everyday physiology as well as synthesis of new tissue. Since photosynthesis is the primary source of ATP, allocation to photosynthetic tissue maximizes developmental potential. But to the degree that a plant grows photosynthetic tissues - often leaves - it is to that degree not enhancing its ability to do other things, like collect soil nutrients or increase its height enough that it can maintain full exposure to light. So when a plant competes with other species, allocation of resources to anything but photosynthetic structures constrains growth; but failure to allocate to other structures constrains accumulation of needed resources. These constraints thus entail a trade-off, and how a species or individual plant specializes itself in response to this forced trade-off determines, or has its expression in, the details of its anatomy and physiology.

Plants face other constraints besides resource limitations. Plants face basic physical constraints, too, limiting possible solutions to trade-offs. Imagine a plant devoting nearly all its growth to its stem and only a small proportion to its leaves and almost none at all to roots. Rootless, it would quickly collapse. So, gravity, set in relation to hypothetical masses of potential plants and even wind velocities, imposes a constraint on which morphologies can survive and compete in certain circumstances. Physiologically, rather than morphologically, plants face other constraints in that for instance a plant without adequate transport structures in its stem would be unable to pass soil nutrients, water, and matter from its roots to its leaves. Also in the physiological realm, plants require enzymes for most of their activities, and thus face a trade-off in producing more of some of these than others. So, a plant's absolute physiological requirements will impose limits on its potential form. But also, the acquisition of a particular form entails relative physiological requirements, too. Such constraints then carry the implication that a certain subset of potential morphologies which might in their absence be expected to survive and compete under some particular circumstances will because of them not succeed. The constraints thus impose limits in possibility space over the sorts of organisms able to survive, under varying soil conditions, wind velocities, humidities, temperatures, and the like (Tilman 1988, 120-123).

Consequently, all the organismal properties determining outcomes in Tilman's $R^{*}$ model can be causally explained by the trade-offs all organisms face and each species' solutions to those trade-offs. An organism's ability to convert a particular resource to reproduction and the minimum resource level at which it can do so $\left(R^{*}\right)$ are obviously functions of its morphology and physiology. But given that simple idea, constraints and trade-offs provide common, quantifiable terms for comparing species' abilities to survive and compete for resources. Together, these constraints and trade-offs, their solutions, and the quantified capacities (like $R^{*}$ ) yielded by these solutions explain why what happens in the idealized circumstances of the resourcecompetition model happens there. In this way, the $R^{*}$ model is subsumed by the constraints and trade-offs framework. In the next section, I characterize this framework.

\section{Channeling Explanations}

Nature rarely offers such idealized circumstances in which these more basic features support the outcomes of the $R^{*}$ model, so explaining the idealized case alone is not yet novel. The explanatory novelty appears when we pay attention to how a constraints and trade-offs framework can handle disturbance. Constraints and trade-offs become components of vegetation explanations by blocking out regions of multidimensional state-space. As in the abstract multi-dimensional spaces used to describe niches, each dimension of the space represents a circumstance relevant to organisms' survival. Constraints and trade-offs block out regions of this space as uninhabitable for organisms with certain characteristics. For example, above and below certain temperatures, hydration and solar radiation levels, no plant can survive. These absolute constraints make regions of state-space uninhabitable by any plant. Then, settling on certain solutions to forced trade-offs like resource-allocation makes narrower regions viable for plants developing according to those solutions, and regions viable on their own become nonviable in various combinations. Assembling nonviable regions then creates channels of viability in state-space, regions in which it is possible for plants to 
survive. Thus, at the most general or abstract explanatory level, plants or vegetation are explained by their viability. However, this explanatory structure handles different levels of generality and specificity.

What is explained by a constrained state-space like one which incorporates only general, universal constraints is not the presence of individual plants, but widespread gradients. Planes within viable regions of state-space can be represented as a gradients along which possible solutions to trade-offs share sets of features. Tilman specifically identifies two gradients as defining forms, functions, and life-histories likely to succeed as conditions vary, a soil resource:light gradient (along which loss-rate is held constant), and a lossrate gradient (along which the first gradient, resources:light, is held constant). Recognizing even a small set of constraints yields "the prediction that all successions should progress, at least initially, from short to tall species. Further, they predict that secondary successions should progress, initially, from rapidly growing species to more slowly growing species" (239). Gradients are therefore widespread regularities. In state-space, they are simple surfaces within regions of state-space that are viable when universal constraints and tradeoffs are introduced. That is, they are explained by state-spaces not making reference to particular natural systems.

Explaining the dynamics of more particular systems involves incorporating further constraints - the constraints at work in those systems - and sometimes adding new dimensions for them to explanatory statespace. As circumstances change over time, new regions of state-space become absolutely uninhabitable, or uninhabitable by organisms with particular characteristics, and changes in vegetation, as in primary or secondary succession, can thus be explained by shifting constraints. Shifting constraints force changes in what characteristics are viable and thus changes in vegetation, against a background of other, stable constraints. For example, at Cedar Creek Natural History Area (CGNHA) in Minnesota (now named 'Cedar Creek Ecosystem Science Reserve'), where Tilman's group has established long-term experimental plots, a common successional sequence runs from annuals and short-lived perennials, to perennial grasses dominated by bluestem, followed by woody plants including oak and white pine. A series of experiments at CGNHA supported the hypothesis that a trade-off between colonization capacity and nutrient-acquisition capacity controls the early, herbaceous portion of succession there, while the later part of succession appears to be controlled by the trade-off between nutrient-acquisition capacity and light-acquisition capacity (Tilman 1990, 11-12). "Control" here means not that these factors are individually responsible for successional dynamics, but rather that shifting constraints have forced observed changes in vegetation, given a certain set of background constraints.

The explanatory strategy just illustrated exemplifies what I label "channeling explanation." An actual state of affairs is channel-explained when shown to remain possible in contrast with a range of other states of affairs which are shown impossible. States of affairs are shown impossible as a function of theory and/or information about an explanandum's circumstances (where, following convention, an "explanandum" is that which is to be explained.) The "channeling" aspect of such explanations is that, in a state-space, adding information about what is impossible channels states of affairs into remaining regions of viability. Constraints on possibility may be absolute, circumstantial, or a combination of the two. Such explanations are especially useful when, as with vegetation, regions of viability are enclosed on more than side, especially in more than one dimension.

A concern about treating channeling explanations as explanatory is that merely being represented as possible is itself a very weak requirement for explanation. Accounts of explanation have traditionally required demonstrating that explananda are made necessary by the explanatory framework, or at least probable, not merely actual, much less possible. For instance, insofar as it does not rule them out, Newtonian Mechanics leaves the existence of elephants possible, but it does not satisfyingly explain them. I would suggest, however, Newtonian Mechanics does add significant information to our understanding of why there are elephants; that having a metabolism is physically possible is a significant part of the explanation of why there are elephants. But it is not the whole explanation.

Even as some channeling-explanations will be unsatisfying, explananda can be channel-explained in degrees. The more alternative possibilities one can rule out, the more information one has about why something, rather than other things, is the case. Even if it can never be shown that an explanandum must be the case, and there are always other possibilities for what could occur in principle, adding circumstantial information can make an explanation converge on the explanandum. When little of state-space can be ruled 
out, channeling explanations will be unsatisfying. But I noted that this form of explanation can be employed for explananda with varying degrees of specificity and abstraction - not only singular states but also general gradients on which it is easier to converge.

Here is an example of explaining a singular state, perhaps the hardest case for channeling explanation - a mature pin oak in a certain woods. Vascular plants like pin oak can survive only in certain ranges of temperature, $\mathrm{pH}$, hydration, and so forth. Like river banks, the circumstances in an area limit viability to only those organisms viable within those limits. Historical ranges in that woods must have been such that it is physiologically possible for a pin oak to germinate and prosper. That does not entail that the oak be there. Nor does it rule out the alternative that a "schmoak" - a hypothetical alien life-form with physiology identical to a pin oak's - appears instead. However, if possible vegetation is further constrained by the contingent history of evolution of plants on Earth, and then further constrained by contingent facts of local biogeography like the availability of oak seeds, an oak becomes one of fewer and fewer possibilities. In this context, information about the presence of local resource-competitors like elms and facts like their $R^{*}$ values can contribute to explaining the oak, too. If the biological world is as tightly packed with competitors as Darwin envisioned in his image of the barrel full of wedges, maximum information about such circumstances can eliminate all but quite specific possibilities.

Not only hypothetical organisms like "schmoaks" remain possible in such state-spaces; real alternatives are possible, too. In one of Tilman's (1983) experimental studies, his group established 36 experimental plots, denuded of vegetation on an old field at CCNHA and fertilized each of the plots with a different nitrogen:magnesium ratio. Their goal was to assess how vegetation establishment would be affected by limiting-resource levels. However, the following year pocket gophers invaded the experimental plots. In the end, though biomass and species-composition varied along the nitrogen:magnesium gradient, gopher mounds were dominated by different species than the other plots. Interestingly, gophers preferentially built mounds on nitrogen-treated plots, so that their effects were correlated with nitrogen treatment. In this example, resource-competition theory alone neither predicts nor explains the gopher-associated dominance of Setaria glauca (Yellow Foxtail) and Polygonum convovulus (Bindweed) over the Agrostis scabra (Rough Bentgrass) and Agropyron repens (Quackgrass), which dominated gopher-free high-nitrogen plots. By the same token, it does not predict or explain the presence of the latter species, either, as competition theory itself does not account for gophers, much less highway planning commissions. It does, however, rule out the establishment of shade-only ferns. Supplemented with further information about available migrants and habitat conditions, it can say which of these migrants can avoid competitive exclusion by others, explaining their presence that way, as long-term viable where the others are not. It offers causal understanding about the presence of Foxtail and Bindweed, and the absence of shade-ferns, while not entailing that those species must or must not be present.

\section{Ghanneling as Explanatory}

Channeling explanation thus offers a way of fitting facts into the causal structure of the world. However, it differs from Wesley Salmon's (1984; 1989) "ontic conception of explanation," which this language otherwise suggests, in that it does not suppose the nomological necessity or even probability of its explanandum. On Salmon's ontic conception, "to explain an event is to exhibit it as occupying its (nomologically necessary) place in the discernible patterns of the world." Channeling explanation provides a way of positioning facts in relation to causes in the absence of a complete causal story, and in the absence of nomological necessity (where causal laws would undergird their effects needing to happen). In suggesting that channeling explanation is neither nomological or nomothetic (i.e., law-based) but also not probabilistic, I do not mean that laws (or probabilities) are never involved. Some regions of state-space eliminated as impossible for plant-growth may be eliminated by true, universal, counterfactual-supporting generalizations. The difference is that except in cases where the explanandum is the entirety of viable possibility space, channeling explanation does not involve deductively deriving an explanandum from any law. It does not assert that the explanandum has to be. Being a mode of explanation rather than an account of what it means to explain, channeling explanation can be useful in disciplines or at levels of description where explanatory 
laws and complete causal stories are not forthcoming, and therefore deductive derivations of explananda are unattainable.

That deductive derivation is essential to explanation has been widely held; Stathis Psillos (2002) comments "the commitment to explanation as a species of deductive derivation has been so pervasive that it can hardly be exaggerated" (283). Descartes, Leibniz, and Mill all held this view (Psillos 2007). More recently, "unificationist" accounts of explanation, like those of Friedman (1974) and Kitcher (1989) treat theories as explanatory when they reduce the number of brute facts in the world, by assimilating them into a single account, as Newton made tides and falling leaves - which beforehand had little to do with one another - each effects of gravitation. On such accounts, ideal explanations are derivations from such unifying theories (Kitcher 1989, 430-432). "Pragmatic" accounts of explanation like those of Achinstein (1984) and van Fraassen (1989) reject this requirement, allowing, as van Fraassen puts it, that "scientific explanations are simply, in my view, those which draw upon science for the adduced information" requested by a whyquestion (186). However, channeling explanations meet a higher bar than the pragmatists set in that they offer a way of presenting causal understanding, even when it is not complete. Analogously, if a rubber duck placed in a river is someplace on the river a few days later, the position of the riverbanks offer a good (if imprecise) explanation of its location. Were the banks impossible to breach (which is to say, free of exceptions), the explanation would be even better.

Channeling explanation bears similarities to two other forms of explanation recently discussed by philosophers, "how-possibly explanations" and "viability" or "design explanations." Conceptually distinct but not conflicting, these other forms of explanation can work together with channeling explanations in practice. Scientific how-possibly explanations have been described by Dray (1957), Brandon (1990), and Forber (2010), especially to make sense of evolutionary explanations such as accounts of adaptation. In contrast with what Dray calls "how-actually explanations," which provide accounts of how or why events actually do occur, how-possibly explanations explain how they might possibly occur. Like channeling explanations, how-possibly explanations establish a set of probabilities or a region of possibility in statespace and explain events by positioning them in that space, sometimes in contrast with other events which could not have occurred. Channeling explanations work subtly but significantly differently, not offering a positive proof of an event's possibility but representing it as not impossible given available information. Blocking out regions of possibility space as impossible, like I have described, does not entail asserting that remaining regions are actually possible, as they may well not be, given additional information. In fact, Forber notes that Brandon uses the apt example of a tropical plant growing in Switzerland. For Brandon, a howpossibly explanation should "show how these plants actually got to Switzerland as well as how it would be possible to cultivate plants in Switzerland's climate" (Forber 2010, 36). Offering a channeling explanation does not require offering such a positive account or narrative.

Arno Wouters has recently described another explanatory structure based on constraints in functional biology. He has called the explanations "viability explanations" (1995) and "design explanations" (2007). With some small differences, they are similar approaches to explaining why organisms have some one trait rather than another. The earlier account of viability explanations focuses on what organisms need, "fit[ting] a trait into a given organism and its environment by showing why it is needed in that organism and its environment" (1995, 437). Having identified a need, viability explanations invoke a functional counterfactual of the form, "if condition $B$ then (if trait $A^{\prime}$ would not be in range $S$ then organism $i$ would have problem $P)$," where trait $A^{\prime}$ being in the range $S$ is what an organism needs to be viable" $(1995,443)$. Wouters's (2007) update, "design explanation," focuses more explicitly on the constraints on what can be alive, which he calls "functional dependencies." Like channeling explanations, these are built around contrasts between actual states of affairs - here, traits - explained by contrast with other hypothetical traits, which for design explanations are those less "useful" for an organism. "In many cases," Wouters suggests, "the hypothetical organism" with some trait swapped out for a hypothetical alternative "cannot live," and this comes close to channeling explanation (2007, 75). However, usefulness is a contrastive concept in design explanations. In them a trait can be explained by slightly increasing an organism's ability to stay alive, such that design explanation presupposes optimization (74). Channeling explanations do not depend on explananda being better in any sense than other viable alternatives, nor on no other alternatives being viable. A more 
significant difference with channeling explanation lies in Wouters's insistence that viability and design explanations are not causal, and explain only synchronically. That is, design explanations do not have a historical dimension, and they do not assert that the constraints or "functional dependencies" they appeal to are causes. Stephen Jay Gould's repeated usage of and gestures towards the explanatory value of constraints, especially as they are can be expressed in "quantified morphospace," is similarly synchronic (Gould 1980). In contrast, channeling explanations shine at handling dynamic systems, like the sequences of changes collectively described as plant succession. Plant succession can be explained by appealing to shifting constraints, which are thus its causes (in the channeling sense described). Consequently, though they differ, it may be useful to group Wouters's forms of design explanation with channeling explanations as species of constraint-based explanation.

\section{Assets of Channeling}

I have argued that in the very case study Weber uses to argue that ecology should be thought to have achieved laws, we find a structure of scientific understanding that is not law-based. Moreover, it is not merely a model, as many other state-space theories are. Unlike models, its claims about what parts of statespace are unrealizable are themselves direct claims about nature. It does not depend on a further hypothesis on behalf of the model that it resembles some part of nature. There is a significant advantage in philosophically understanding Tilman's scientific reasoning this way. It lies in how potential exceptions can be incorporated.

As I have characterized them, channeling explanations can draw on a great deal of supplementary information about particular, local conditions. This might raise a suspicion: if the $R^{*}$ model were also allowed to be supplemented with such information, could its exceptions be accounted for? Not straightforwardly, I suggest. The obstacle for causal regularities lies in incorporating disturbing conditions. For example, in the case of the gopher invasion at CGNHA, the $R^{*}$ model alone would support the prediction that the plant with the lowest $R^{*}$ for nitrogen would dominate those plots. Then, supplemented with information about gophers, it could be supplemented with a further causal regularity of the form, "except that when gophers invade, vegetation is modified so." Remember that the $R^{*}$ model is itself a stopgap for an exception. If we think about ecological understanding this way, the structure of understanding becomes a potentially unending series of clauses - exceptions to exceptions to exceptions.

Happily for ecology, researchers in animal behavior, meteorology, and other disciplines analyzing phenomena affecting ecology's domain $d o$ have bodies of rich causal understanding about such domains. A state-space representation of constraints provides a structure for incorporating their theory as constraints on vegetation. Compare this way of incorporating further constraints with incorporating further causal understanding into mathematical expressions like the Lotka-Volterra competition equations. With such equations, additional theory can be incorporated only by adding terms to the equations, making them increasingly intractable and raising the burden on data-collection to make values come out correctly (even presuming all relevant terms can actually be incorporated). In contrast, the channeling explanation framework captures ecological theory's modularity - its capacity to connect other bodies of theory with its domain to produce understanding.

One might yet resist channeling-explanations as explanations, on the grounds that they will always be partial if they do not deductively entail their explananda. I have noted that the gap between channelingexplanations and deductive entailment can be quite large when only very general constraints are invoked and the explanandum is very particular. Such explanations will be unsatisfying, as it would be to explain the birth of Jumbo the elephant by pointing to it not being disallowed by classical thermodynamics. Yet, I have described how more specificity can be added to explanations by incorporating further relevant constraints, and this possibility reveals a further asset: it makes sense of the very idea of a partial causal explanation in the absence of laws. Railton (1981) has offered one of the best accounts of what it means to offer a partial explanation, suggesting that it involves offering information about an "ideal explanatory text" which stands behind the explanandum. Railton presumes that the nodes in the ideal explanation are connected by laws, but Woodward (2003), responding to Railton, suggests a range of cases in which information about an ideal 
explanatory text is no explanation at all, and that includes when relevant causal laws are known (175-181). Without causal laws, it is very difficult to make sense of a partial causal explanation on a deductivist account of explanation. In a channeling framework however, it is straightforward: every constraint is causally related to explananda in its state space, and a partial explanation is one that cites some subset of those constraints. If this makes all channeling explanations partial explanations, that simply reflects that scientific disciplines operate at different levels of description and that ecological explanations can combine with those from other levels. Just to be able to understand how an ecological explanation might be both causal and partial is a boon.

\section{Conclusion}

The channeling framework represents one way ecologists have structured explanatory theory despite the wealth of exception-producing causal factors in its domain. For its part, Weber's attempt to identify law-like regularities in competition theory productively explores the limits of the Newtonian ideal in contemporary ecology. Ecology would certainly derive considerable status from meeting that ideal, and it will be useful to continue searching for laws, like Dodds, Colyvan, and Ginzburg have. Yet, because of the explanatory power of laws, philosophers of science have sometimes approached the special sciences as if with law-divining rods. When generalizations appear, philosophers have worked to understand them as laws, often by weakening "law" to include ceteris paribus generalizations, generalizations holding over a limited range of invariance, inference rules, non-universal causal regularities, and the like. My re-analysis of Weber's case suggests that this well-motivated habit can obscure non-nomological forms of understanding and explanation. Just as this branch of ecology appears stronger described on its own terms, philosophy of ecology is likely to transcend its adolescence by recognizing other ways in which ecologists approach their domain that do not conform to the expectations of the Newtonian Ideal.

\section{Literature cited}

Achinstein, P. 1984. The pragmatic character of explanation. In PSA 1984: Proceedings of the Biennial Meeting of the Philosophy of Science Association. Ed. by P.D. Asquith and P. Kitcher.

Beatty, J. 1981. What's wrong with the received view of evolutionary theory? In PSA 1980: Proceedings of the Biennial Meeting of the Philosophy of Science Association. Ed. by P.D. Asquith and R.N. Giere.

Beatty, J. 1995. The evolutionary contingency thesis. In Concepts, Theories, and Rationality in the Biological Sciences. Ed. by G. Wolters and J.G. Lennox, Pittsburgh: University of Pittsburgh Press.

Begon, M., Harper, J.L., and Townsend, C.R. 1990. Ecology: Individuals, Populations, and Communities. Boston: Blackwell.

Brandon, R. 1990. Adaptation and Environment. Princeton: Princeton University Press.

Cartwright, N. 1989. Nature's Capacities and their Measurement. Oxford: Oxford University Press.

Cartwright, N. 2002. In favor of laws that are not ceteris paribus after all. Erkenntnis 57: 425-439.

Castle, D.G.A. 2001. A semantic view of ecological theories. Dialectica 55: 51-65.

Golyvan, M. and Ginzburg, L.R. 2003. Laws of nature and laws of ecology. Oikos 101: 649-653.

Cooper, G.J. 2003. The Science of the Struggle for Existence: On the Foundations of Ecology. Cambridge: Cambridge University Press.

Dodds, W.K. 2009. Laws, Theories, and Patterns in Ecology. Berkeley: University of California Press.

Dray, W. 1957. Laws and Explanation in History. Oxford: Oxford University Press.

Earman, J. and Roberts, J. 1999. Ceteris paribus, there is no problem of provisos. Synthese 118: 439-478.

Forber, P. 2010. Confirmation and explaining how possible. Studies in History and Philosophy of Biological and Biomedical Sciences 41: 32-40.

Friedman, M. 1974. Explanation and scientific understanding. The Journal of Philosophy 71: 5-19.

Ginzburg, L.R. and Colyvan, M. 2004. Ecological Orbits: How Planets Move and Populations Grow. Oxford: Oxford University Press. 
Gotelli, N.J. 2008. A Primer of Ecology. Sunderland: Sinauer Associates, 4th ed.

Gould, S.J. 1980. The evolutionary biology of constraint. Daedalus 109: 39-52.

Grinnell, J. 1904. The origin and distribution of the Chestnut-backed Chickadee. Auk 21: 364-382.

Hardin, G. 1960. The competitive exclusion principle. Science 131: 1292-1297.

Hutchinson, G.E. 1957. Concluding remarks. Cold Spring Harbor Symposia on Quantitative Biology 22: 415-427.

Hutchinson, G.E. 1961. The paradox of the plankton. American Naturalist 93: 145-159.

Kingsland, S.E. 1995. Modeling Nature: Episodes in the History of Population Ecology. Chicago: University of Chicago Press, 2nd ed.

Kitcher, P. 1989. Explanatory unification and the causal structure of the world. In Scientific Explanation: Minnesota Studies in the Philosophy of Science, vol. 13. Ed. by P. Kitcher and W.C. Salmon. Minneapolis: University of Minnesota Press.

Kullberg, R.G. 1982. Algal succession in a hot spring community. American Midland Naturalist 108: 224244.

Lange, M. 1993. Natural laws and the problem of provisos. Erkenntnis 38: 233-248.

Lange, M. 2002. Who's afraid of ceteris paribus laws? or: How I learned to stop worrying and love them. Erkenntnis 57: 407-423.

Lawton, J.H. 1999. Are there general laws in ecology? Oikos 84: 177-192.

Lewontin, R.C. 2003. Science and simplicity. New York Review of Books 50(7): 39-43.

Lloyd, E.A. 1988. The Structure and Confirmation of Evolutionary Theory. Westport: Greenwood.

Nagel, E. 1961. The Structure of Science: Problems in the Logic of Scientific Explanation. New York: Harcourt, Brace \& World.

O'Hara, R.B. 2005. The anarchist's guide to ecological theory. or, we don't need no stinkin' laws. Oikos 110 : 390-393.

Park, T. 1948. Competition between populations of the flour beetles, Tribolium confusum duval and Tribolium castaneum herbst. Ecological Monographs 18: 267-307.

Peters, R.H. 1991. A Critique for Ecology. Cambridge: Cambridge University Press.

Poulin, R. 2007. Are there general laws in parasite ecology? Parasitology 134: 763-776.

Psillos, S. 2002. Causation and Explanation. Montreal: McGill-Queen's University Press.

Psillos, S. 2007. Past and contemporary perspectives on explanation. In General Philosophy of Science: Focal Issues (Handbook of the Philosophy of Science). Ed. by T. Kuipers. North-Holland: Elsevier.

Railton, P. 1981. Probability, explanation, and information. Synthese 48: 233-256.

Roughgarden, J. 2009. Is there a general theory of community ecology? Biology and Philosophy 24: 521529.

Salmon, W.C. 1984. Scientific Explanation and the Causal Structure of the World. Princeton: Princeton University Press.

Salmon, W.G. 1989. Four decades of scientific explanation. In Scientific Explanation: Minnesota Studies in the Philosophy of Science, vol. 13. Ed. by P. Kitcher and W.C. Salmon. Minneapolis: University of Minnesota Press.

Sarkar, S. 1996. Ecological theory and anuran declines. Bioscience 46: 199-207.

Shrader-Frechette, K.S. and McCoy, E.D. 1993. Method in Ecology. Cambridge: Cambridge University Press.

Silvertown, J.W. 1983. The distribution of plants in limestone pavement: Tests of species interaction and niche separation against null hypotheses. The Journal of Ecology 71: 819-828.

Sober, E. 1984. The Nature of Selection: Evolutionary Theory in Philosophical Focus. Cambridge, MA: MIT Press.

Suppe, F. 2000. Hempel and the problem of provisos. In Explanation and Rationality: Aspects of the Philosophy of Carl G. Hempel. New York: Oxford University Press.

Thompson, P. 1988. The Structure of Biological Theories. Albany: SUNY Press.

Tilman, D. 1980. Resources: a graphical-mechanistic approach to competition and predation. American Naturalist 116: 362-393.

Tilman, D. 1982. Resource Competition and Community Structure. Princeton: Princeton University Press. 
Tilman, D. 1983. Plant succession and gopher disturbance along an experimental gradient. Oecologia 60: 285-292.

Tilman, D. 1988. Plant Strategies and the Dynamics and Structure of Plant Communities. Princeton: Princeton University Press.

Tilman, D. 1990. Constraints and tradeoffs: toward a predictive theory of competition and succession. Oikos 58: 3-15.

Udvardy, M.F.D. 1959. Notes on the ecological concepts of habitat, biotope and niche. Ecology 40: 725728.

van Fraassen, B.C. 1989. Laws and Symmetry. Oxford: Oxford University Press.

Vellend, M. and Agrawal, A. 2010. Conceptual synthesis in community ecology. The Quarterly Review of Biology 85: 183-206.

Waters, C.K. 1998. Causal regularities in the biological world of contingent distributions. Biology \& Philosophy 13: 5-36.

Weber, M. 1999. The aim and structure of ecological theory. Philosophy of Science 66: 71-93.

Woodward, J. 2003. Making Things Happen: A Theory of Causal Explanation. New York: Oxford University Press.

Wouters, A.G. 1995. Viability explanation. Biology \& Philosophy 10: 435-457.

Wouters, A.G. 2007. Design explanation: Determining the constraints on what can be alive. Erkenntnis 67: 65-80.

\section{AGKNOWLEDGMENTS}

The germ of this article was in my dissertation research, and I thank John Beatty, Helen Longino, Ron Giere, and especially Ken Waters for support at that stage. More recent writing was enhanced by a stimulating research fellowship at Sydney Centre for the Foundations of Science. I thank audience members at ISHPSSB, University of Tennessee, University of Cologne, and University of Sydney for useful questions, especially Paul Griffiths and David BraddonMitchell. Finally, three anonymous referees for this journal provided thoughtful analysis. I appreciate the help.

Copyright (C) 2011 Author(s).

This is an open-access article distributed under the terms of the Creative Commons Attribution-NonCommercial-NoDerivs license, which permits anyone to download, copy, distribute, or display the full text without asking for permission, provided that the creator(s) are given full credit, no derivative works are created, and the work is not used for commercial purposes.

ISSN 1949-0739 